\title{
Marketing Decision Making Behavior under the Influence of Attractive Performance-linked Rewards
}

\author{
Abhishek Pathak ${ }^{1}$ \& Lewis K S Lim² \\ ${ }^{1}$ Post Doctoral Research Fellow, Institute on Asian Consumer Insight, Nanyang Business School, Nanyang \\ Technological University, Nanyang Avenue, Singapore \\ 2 Associate Professor of Marketing Practice, Nanyang Business School, Nanyang Technological University, \\ Nanyang Avenue, Singapore \\ Correspondence: Abhishek Pathak, Institute on Asian Consumer Insight, Nanyang Business School, Nanyang \\ Technological University, S3-B1C-15, Nanyang Avenue, Singapore.
}

Received: April 4, 2016

Accepted: May 3, 2016

Online Published: May 5, 2016

doi:10.5430/ijba.v7n3p81

URL: http://dx.doi.org/10.5430/ijba.v7n3p81

\begin{abstract}
Salaries of managers across many firms have sizeable performance-linked reward components. Conventional wisdom suggests that these performance-linked rewards are effective in keeping employees motivated and innovative. However, recent psychological research indicates that overly-attractive rewards may in fact reduce performance and be counterproductive for an otherwise high performing team. This issue has important implications for design of compensation schemes for marketing managers. Yet, few marketing management researchers have studied this phenomenon. How do performance-linked rewards influence the decision making styles of marketing managers who have to be innovative in dealing with competition? Does the promise of attractive performance-linked rewards help or hinder performance of a marketing unit? We sought to answer these questions via a simulation study in which we examined decision making processes and performance changes under different levels of performance-linked incentives. Findings from the study provide new insights into the link between performance-linked rewards, decision making processes, and actual performance of managers. This research contributes prescriptions for calibration of compensation structures in order to promote more prudent decision making processes and to drive greater performance.
\end{abstract}

Keywords: performance-linked rewards, risk-taking tendencies, innovation, markstrat simulation

\section{Introduction \& Overview}

Performance-linked remuneration is a norm in many leading firms worldwide. Top management is often subject to media and shareholder criticism due to the publicity of their large performance bonuses. Even middle-level managers are not spared from media scrutiny when it is discovered that they are paid large performance-linked bonuses.

Does the promise of large performance-linked rewards help or hinder performance? Studies in this area have provided mixed results: some studies point to increased performance whereas others point towards decreased performance when managers are promised large financial rewards tied to their performance levels. Lazear (2000), for example, found that performance-based compensation motivates people to increase their effort and subsequently their output. Similar studies by Camerer and Hogarth (1999), on the other hand, showed inconclusive results. Their research revealed that incentives sometimes improve performance, but often they do not. They found that incentives improve performance in easy tasks that are effort-responsive but the same incentives hurt performance when the problems are too difficult or require harder thinking. Similar studies in sports by Dandy et al. (2001) done on top basketball players indicated that free-throw shooting performance among the basketball players was worse during games when the stakes are high than during training. A recent study by Ariely et al. (2009) points in similar direction, that across many multiple tasks, higher monetary incentives lead to a worse performance.

The lack of clarity in this field motivated us to carry out further research. In this study, we extend the analysis of reward-performance effect to the marketing management context. We examine marketing managers' decision making behavior and performance when the personal stakes of management are high. Specifically, we look at how the promise of attractive rewards skews the risk aversion of managers and their propensity to innovate, and in turn 
their performance outputs. We also analyze how the degree of challenge in the performance targets as well as in the existing performance levels moderate the effects of attractive rewards on decision making processes and eventual performance.

\section{Theoretical Background}

Management practitioners, having being heavily influenced by the economic principles, have often subscribed to the well-established relationship between motivation, effort and performance. Psychologists on the other hand have reported many cases where increased motivation can in fact decrease the performance (Baumeister, 1984). Threats to sub-optimal performance include excessive competitiveness, evaluation apprehension in the presence of an audience, and certain ego-related personality factors (Baumeister \& Showers, 1986).

The classic Yerkes-Dodson law (Yerkes \& Dodson, 1908) suggests that there is an optimal level of motivation for any task and any departure from this level in either direction will have detrimental effect on performance levels.

Studies have shown decreases in performance levels in tasks that involve highly practiced, automatic skills in the presence of cash incentives or bonuses attached to the task outcome (Baumeister, 1984; Langer \& Imber, 1979). Apparently, such performance-linked bonuses or incentives make the doer aware of the task more than he/she is used to, which decreases the performance of the subject.

A further extension of the effect was provided by McGraw \& McCullers (1978) who showed that the introduction of monetary rewards reduces performance even in some problem-solving tasks.

In recent studies, Lazear (2000) found that when a big company shifted its practice of an hourly wage to a piece rate pay, the productivity enhanced by a massive forty four percent. In this study, Lazear showed that when two schemes - output in performance-linked schemes versus output when remuneration is independent of the effort, were compared, the latter was often better.

Some other researchers too have documented similar results, where subjects who were not paid at all exerted greater effort than those who were paid monetarily (Gneezy \& Rustichini, 2000).

The social psychology literature provides extensive evidence tying the relationship between arousal, attention and performance (Fenigstein \& Carver, 1978; Wegner \& Giuliano, 1980). Social researchers argue that even the presence of a supportive audience can shift the focus from a well learned task to the mechanics of the task which leads to a detrimental performance level (Butler \& Baumeister, 1998).

Baumeister (1984) also argues that the rewards induce arousal and increase self consciousness at the same time and both of these processes in turn shift the focus to self rather than to the task at hand and such enhanced self consciousness can disrupt well learned skills which are important in completing the task successfully (Baumeister, 1984; Dandy et al 2001). We believe that successful managerial tasks are no different from these challenges. We believe that the 'high reward induced' arousal can bring about self consciousness in a manager in a similar way and may shift the managerial focus to self rather than to the task and may lead to a detrimental performance level.

We augment our arguments using two popular theories in social psychology - distraction theories and self- focus theories. Distraction theories argue that performance pressure creates a distracting environment which in turn shifts the focus of an individual to task-irrelevant cues like worries and to the consequences of the failures (Wine, 1971; Beilock \& Carr 2001). So we argue that before the introduction of the pressure of performance-linked reward, the manager is used to a single focused task and is used to excelling in that task but after the introduction of a reward pressure, the same task now turns into a dual task (Beilock \& Carr, 2001) and the managerial control over the task may slip as the worries and the consequences of the performance and a notional future loss in cases of non-performance compete for his attention simultaneously, thereby leading to a detrimental performance.

Taking support from self-focus theories (execution focus theories) we can also argue that the performance pressure shifts the attention of a manager from the task at hand to an increased level of self-consciousness and to an increased reward induced anxiety. This enhanced self-consciousness in turn increases the managerial attention to skilled processes involved in the task and on their step by step control which earlier was an automatic process before the introduction of performance-linked reward (Baumeister 1984; Lewis \& Linder 1997; Beilock \& Carr, 2001).

Self-focus theories also argue that such enhanced self consciousness to a well- learned skilled task is detrimental to its execution and may disrupt the performance levels (Kimble \& Perlmuter, 1970; Langer \& Imber, 1979; Lewis \& Linder, 1997; Beilock \& Carr, 2001). Although these theories may look like contrasting at first, but when applied to pressure induced by performance-linked rewards in a managerial task, both these theories support our argument as the performance-linked rewards distract the focus and also increase the self consciousness at the same time. 
Our primary goal in this study is to extend the findings of social psychology to the managerial domain. Although theoretically there may seem to be similarities between the pressures of performance in a managerial task and the pressures of performance in any other skilled task like golf or sports and it may also seem that the mechanisms affecting both are the same; but research tying them together and providing evidence in its support is lacking.

The differentiating factor in our work and other similar works in this area is that most researchers have used nonmanagerial tasks like physical labor, sports or skilled motor performance in a game under performance-linked incentives to reach their conclusions whereas we use Markstrat, which simulates the real life managerial performance to discover new evidence and to arrive at our conclusion. In short, we apply the generalizations of social psychology to the real life managerial behavior through a simulation which brings in more realism to the evidence.

\section{Hypotheses}

In the current research, we seek to examine marketing managerial decision making behavior under the influence of highly attractive performance-linked rewards. Specifically, we study how the promise of large rewards tied to managers' performance, affect the managers' decision making processes and style (e.g., risk preference, propensity to innovate etc) and consequently their actual performance levels under conditions of less challenging versus highly challenging performance targets as well as under conditions of low versus high existing performance levels.

We believe that the high rewards can deviate managers from devoting enough attention to the task towards thinking too much about the associated rewards, thereby shifting the mental task processing of these problems from an "automatic" to a more "controlled" mode (Areily et al 2009; Langer and Imber, 1979; Camerer, Loewenstein \& Drazen, 2005). This phenomenon has been found to be detrimental in sports (Dandy, Brewer \& Tottman, 2001) and we believe it can be detrimental in managerial tasks as well.

Psychologists also provide evidence that too much increased focus on a task also tends to narrow down an individual's focus of attention (Easterbrook, 1959; Areily et al 2009) which may affect the quality of outcomes especially in the creative and mental tasks where both the depth and the innovativeness of a solution clearly provides the winning edge. We believe that managerial tasks too involve creative and out of the box solutions especially in situations where high performance-linked rewards are involved. We also believe that, when high performance-linked rewards are announced, the associated problems too are extraordinary and merit creative solutions from the managers. This creativity needs an open minded thinking (Areily et al 2009) and too much attention on the reward can stifle the creativity, entrepreneurship and innovativeness, thereby reducing the managerial performance (McGraw \& McCullers, 1979).

Based on the above mentioned arguments, we believe that the high performance linked rewards may actually reduce the performance levels of mangers in highly challenging task, may reduce the risk taking tendencies and innovativeness shown by the managers. These arguments lead us to form the following hypotheses:

H1a: The provision of highly attractive performance-linked rewards leads to higher performance levels (as compared to the absence of highly attractive rewards) when performance targets are less challenging

H1b: The provision of highly attractive performance-linked rewards leads to lower performance levels (as compared to the absence of highly attractive rewards) when performance targets are highly challenging

H2a: The provision of highly attractive performance-linked rewards leads to increased risk-taking tendencies (as compared to the absence of highly attractive rewards) when the existing performance level is low

H2b: The provision of highly attractive performance-linked rewards leads to reduced risk-taking tendencies (as compared to the absence of highly attractive rewards) when the existing performance level is high

H3a: The provision of highly attractive performance-linked rewards leads to an increased propensity to innovate (as compared to the absence of highly attractive rewards) when the existing performance level is low

H3b: The provision of highly attractive performance-linked rewards leads to a reduced propensity to innovate (as compared to the absence of highly attractive rewards) when the existing performance level is high

\section{Methodology}

We collected data from undergraduate marketing classes using a computer-based marketing strategy simulation game called Markstrat (Larréché \& Gatignon, 2003). Markstrat is an educational simulation in which students, acting as managers for hypothetical firms, make strategic marketing decisions under varying computer-simulated scenarios representing changing marketplace conditions. Teams of students compete with one another, so the game also simulates a competitive industry environment. Each week, students have to make a series of decisions concerning 
market segmentation, marketing mix, distribution, research and development, production and market research in response to the previous week's competitive outcome. Their performance is measured in terms of financial results (including stock price, profits, and return on investment) they produce for the hypothetical firms they manage. The game is used in many educational institutions as well as companies to hone the decision making skills and enhance the abilities of participants to perform under competitive pressure and uncertainty. Because the game is highly engaging and participants take their managerial decision making tasks in the game very seriously, it provides a high degree of psychological realism as a setting for studying managerial decision making processes.

Two minimally-intrusive small surveys were also conducted during the Markstrat exercise which lasted for a total of eight weeks. The Markstrat software also automatically captures decisions made by each team and details of the simulated marketplace environment and performance outcomes each week, so we were able to obtain records of team actions, marketplace conditions, and team performance from the software database without having to conduct lengthy surveys.

Testing our hypotheses required measuring the decision making behaviors and performance outcomes under varying reward attractiveness levels, varying degree of challenges in performance targets and under varying performance levels.

Because the Markstrat simulation is a graded component of the class, we can expect high degree of participation. Specifically, to create the condition of highly attractive performance-linked rewards and challenging performance target, in one of the periods we offered a monetary incentive to the team in each industry that makes the greatest improvement over its previous period's stock price index (a performance metric over which the team has little direct control) and, furthermore, subject to a minimum percentage improvement. To create the condition of highly attractive performance-linked rewards and less challenging performance targets, in another period we offered a monetary incentive to the team in each industry that makes the greatest improvement over its previous period's retail sales performance (a performance metric over which the team has greater direct control). Other periods were characterized by the absence of such attractive rewards.

Students worked in teams of three or four each, and altogether there were forty eight teams across various class sections who decided to participate in this study. We conducted the study across two courses spread over one year to build an adequate sample size.

Participating teams also filled out a survey questionnaire on two occasions during the eight-week simulation training; between periods $3 \& 4$ and later between periods $6 \& 7$. All other data (including decision, environmental, and performance measures as well as the qualitative data on decision making processes) was drawn directly from the Markstrat software database and the students' memos.

\section{Analysis and Results}

\subsection{Establishing Association between the Performance-linked Rewards and the Performance Levels}

We measured the performance level of teams by comparing them in terms of Net contribution, Market share by value, Market share by unit, Retail sales, Volume sold and Stock Price index (SPI).

An independent-sample t-test was conducted to compare the performance levels after the reward manipulation in periods 4 and in period 7. We found a significant difference in the performance levels of teams between periods 4 and 5. We found that except for the market share by value and by unit, all other performance metrics were significantly higher in period 5 . This suggests that the reward manipulation did have a significant effect on the team performances between these periods. This phenomenon is clearly evident in all the teams, across all the industries and provides support to H1a. (Period 4- Stock price index- $M=1237.6, S D=189.4$, Revenue- $M=56746.4$, $S D=$ 9704.4, Net contribution- $M=22481.9, S D=5757.7$, Market share by value- $M=20.39, S D=3.02$, Retail sales$M=86919.93, S D=15058.4$, Market share by unit- $M=20.41, S D=2.8$, Volume sold- $M=235577.9, S D=38683.6$;

Period 5- Stock price index- $M=1679.5, S D=662$, Revenue- $M=107393.9, S D=48274.8$, Net contribution- $M=43059$, $S D=31316$, Market share by value- $M=21, S D=9$, Retail sales- $M=164512.4, S D=74629.6$, Market share by unit$M=21.1, S D=9.3$, volume sold- $M=413335.7, S D=192896.9 ;$ T values and significance levels- Stock price index- $t$ $(94)=-4-446, p<0.01$, Revenue- $t(94)=-7.12, p<0.01$, Net contribution- $t(51)=-4-47, p<0.01$, Market share by value- $t(57)=-0.47, p=0.64$, Retail sales- $t(50)=-7.06, p<0.01$, Market share by unit- $t(94)=-0.558, p=0.57$, Volume sold- $t(50)=-6.26, p<0.01)$.

In this research, we are interested in the effect of performance-linked manipulation on the low performers versus the high performers, so it is prudent to look at the performance level differences between these two groups in periods 4 -5. Since the performance-linked reward at this stage was for bringing the highest increase in the retail sales, we 
looked at it specifically in these two groups. We found that although the groups differ in terms of average retail sales growth, this difference is not significant. (Low performers- $M=31980.5, S D=42893$.8; High performers, $M=34468$. $6, S D=86095.5 ; t(28)=-0.1, p=0.921)$.

It suggests that although these groups were very different in terms of overall performance, as we found in their Stock Price index differences, we still find evidence that in an effort to get the performance-linked reward, both these groups performed with equal zeal and that the high performers were not leading in terms of growth of the retails sales when compared to low performers.

If we look closely at the percentage growth of retail sales in the high performers, we find interesting results. We find that the percentage growth in retail sales for high performers actually decreased in this period although not significantly (Percentage growth Retail sales till period 4- $M=39.09, S D=57.4$; Percentage growth Retail sales between period $4 \& 5-M=22.68, S D=39.78 ; \mathrm{t}(28)=0.910, p=0.37)$. But there is no explanation for this behavior as these firms were doing well overall and should not have reduced the retail sales in a period when there is performance-linked reward and also when the retail sales is a very easy variable to influence by the teams.

We also find interesting results when we specifically looked at the differences between low performers and high performers between period 7 and 8 (15 teams with lowest SPI in period 7 versus 15 teams with highest SPI in period 7). When we compared the average percentage increase in the SPI till period 7 of these teams with the percentage increase in SPI between periods 7-8, we found that the performance of high performers actually had dipped significantly in this period (Period 7- $M=27.35, S D=13.8$; Period 8- $M=13.38, S D=15.6 ; t(28)=2.59, p=0.015$ ). But the performance of low performers had gone up in the same period although not significantly. (Period 7- $M=0.15$, $S D=2.53$; Period $8-M=3.72, S D=16.8 ; t(28)=-0.882, p=0.385)$.

Given that this is a contradictory finding as opposed to everyday behavior; we specifically looked at the behavior of high performers. We found that the average SPI growth per period among all the firms till period 8 was $29 \%$, so in the next analysis we excluded the firms which had more than $29 \%$ growth in SPI between period 7 and 8 as outliers (though inclusion of such teams would skew the data more in our favor). Next, we excluded the firms having negative SPI growth in Period 8 (because we are interested in the behavior of high performing teams only). A total of 33 firms were remaining; we then compared the average SPI growth of these firms till period 7 with the SPI growth between periods 7 and 8 . We found that the high performers significantly lag in the reward manipulation periods 7 and 8. (Period 7- $M=11.97, S D=6.96$; Period 8- $M=7.36, S D=11.5 ; t(64)=1.97, p=0.053)$.

This interesting finding intrigued us and we looked further at the highest performing teams in the simulation (firms having average SPI growth of $>15 \%$ per period) and the lowest performers. We found the following:

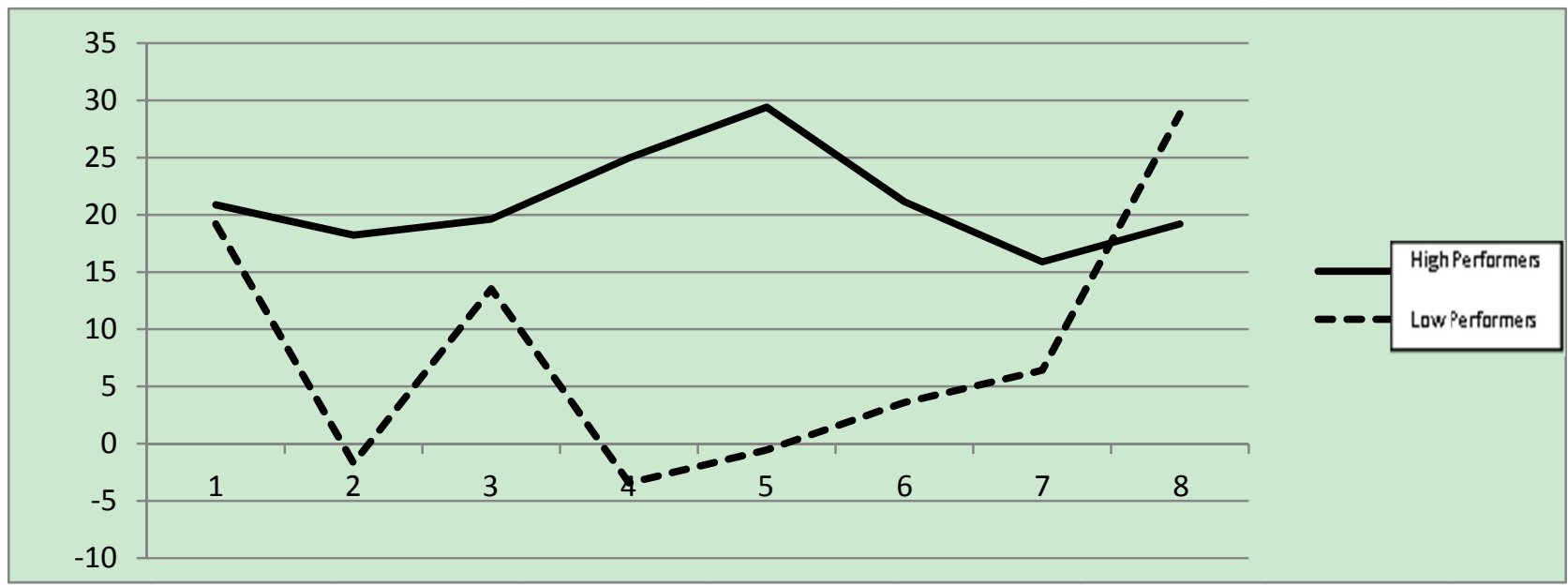

Figure 1. Comparison - high versus low performers

The figure shows a dip in the performance between period 7 and 8 for high performers whereas contrasting results are seen for low performers who were found to be consistently lagging throughout the simulation but still increased the performance levels between periods 7 and 8 . 
One alternative explanation can be that the low performing firms may have given a 'final push' considering it's the last period of a graded course whereas the high performers are not worried about grades as their scores had been consistently high. But that still does not explain the dip in the performance of high performers in period 7; these teams were the best contenders for the performance-linked reward till period 7 but still did not put in an aggressive effort for the reward but in contrast actually lowered their performance in this period.

Based on the above mentioned findings and arguments, we find that $\mathrm{H} 1 \mathrm{~b}$ is not fully supported across all the teams in all the industries. But at the same time, we also find this hypothesis to be specifically supported by high performing teams only, which actually is a counterintuitive phenomenon we actually did not originally hypothesize.

\subsection{Performance-linked Rewards and Risk Taking Tendencies in Less Challenging Tasks versus Highly Challenging} Tasks

We compared the risk taking tendencies - Advertising expenditure, Advertising research expenditure, Sales force, Market research studies and Research and development costs of the low performers with the high performers between periods 4 and 5 (15 lowest performing teams as per Stock price index in period 4 versus 15 highest performing teams). We find that the low performers have taken significant risks in this period and these risk taking tendencies are significantly higher when compared to the previous periods. This evidence provides full support to H2a. (Low performers- Period 4- Advertising expenditure - $M=4870, S D=547.7$, Advertising research expenditure - $M=$ 569.33, $S D=133.21$, Sales force $-M=2213.93, S D=437.2$, Market research studies $-M=429.4, S D=65.7$ and Research and development costs - $M=877.4, S D=569$; Period 5- Advertising expenditure - $M=5288, S D=732.14$, Advertising research expenditure $-M=736.26, S D=245.9$, Sales force $-M=2399, S D=428.84$, Market research studies $-M=465.4, S D=56.13$ and Research and development costs $-M=1452.2, S D=650.18$; $\mathrm{T}$ values and significance levels- Advertising expenditure $-t(28)=-1.771, p=0.087$, Advertising research expenditure $-t(28)=-$ 2.311, $p=0.028$, Sales force $-\mathrm{t}(28)=-1.17, \mathrm{p}=0.252$ Market research studies $-\mathrm{t}(28)=-1.616, \mathrm{p}=0.117$, Research and development costs $-t(28)=-2.576, p=0.016)$.

We find the opposite results among the high performers. Except for one variable, sales force increase, rest all other risk taking measures have not increased significantly unlike the low performers. This provides support that the high performers may not have taken as many risks for the performance-linked reward as the low performing teams and provides support to H2b. (High performers- Period 4- Advertising expenditure - $M=5021.2$, $S D=698.37$, Advertising research expenditure - $M=615.3, S D=180.9$, Sales force- $M=2270.5, S D=317$, Market research studies - $M=440.1, S D=73.4$ and Research and development costs- $M=1304.8, S D=762$; Period 5- Advertising expenditure $-M=5409, S D=712.54$, Advertising research expenditure $-M=690, S D=238.56$, Sales force $-M=$ 2655.86, $S D=503.45$, Market research studies $-M=487, S D=88.47$ and Research and development costs $-M=1271.6$, $S D=733.8 ; \mathbf{T}$ values and significance levels- Advertising expenditure $-t(28)=-1.506, p=0.143$, Advertising research expenditure $-t(28)=-0.967, p=0.342$, Sales force $-t(28)=-2.508, p=0.018$, Market research studies $-t$ $(28)=-1.579, p=0.126$, Research and development costs $-t(28)=0.122, p=0.904)$.

As another measure, we performed a regression analysis, with all the risk taking variables - Advertising expenditure, Advertising research expenditure, Sales force, Market research studies and Research and development costs, as the independent variables and Stock price index (SPI) at period 4 as the dependant variable. We found that for the low performers, the regression model is not significant at the end of period $4\left(F=1.278, d f=5,9,14, p=0.352 ; R^{2}=\right.$ 0.415 ) and the individual beta coefficients of all the variables too were not significant (Advertising expenditure- $\beta$ $=0.303, p=0.215$; Advertising research expenditure- $\beta=-0.047, p=0.966$; Sales force- $\beta=0.464, p=0.339$, Market research studies- $\beta=1.767, p=0.386$ and Research and development cost- $\beta=0.094, p=0.604$ ).

However the same regression model after the reward manipulation condition at the end of period 5 is found to be significant $\left(F=4.767, d f=5,9,14, p=0.021 ; R^{2}=0.726\right)$. Even the individual beta coefficients of Advertising expenditure, Sales force and Research and development cost had turned significant. (Advertising expenditure- $\beta$ $=0.429, p=0.080$; Advertising research expenditure- $\beta=-0.928, p=0.227$; Sales force- $\beta=0.614, p=0.074$, Market research studies- $\beta=3.851, p=0.39$ and Research and development cost- $\beta=0.401, p=0.052$ ).

It provides support to $\mathrm{H} 2 \mathrm{a}$ that the performance-linked reward at the end of period 4 provided sufficient motivation to the low performing teams to increase their risk taking tendencies and to perform better.

However, among the high performers we found interesting results. The same regression model at the end of both the periods 4 and 5 was found to be significant (Period $4-F=4.767, d f=5,9,14, p=0.021 ; R^{2}=0.726$ (Advertising expenditure- $\beta=.429, p=0.080$; Advertising research expenditure- $\beta=-0.928, p=0.227$; Sales force- $\beta=0.614, p$ $=0.074$, Market research studies- $\beta=3.851, p=0.39$ and Research and development cost- $\beta=0.401, p=0.052$; 
Period 5- $F=5.463, d f=5,9,14, p=0.014, R^{2}=0.752$ (Advertising expenditure- $\beta=-0.009, p=0.785$; Advertising research expenditure- $\beta=0.158, p=0.235$; Sales force- $\beta=0.028, p=0.613$, Market research studies- $\beta=0.986, p$ $=0.032$, Research and development costs- $\beta=0.040, p=0.079$ ).

In the case of high performers, we argue that all the risk taking tendencies were expected to be high and that is the very reason these are the better performing teams when compared to low performers. But the research question we are exploring here is the linkage between the performance-linked reward and enhancement in performance levels.

As per our analysis, this linkage is difficult to establish because despite the performance-linked reward, high performers did not increase the performance levels as much as the low performers.

Even between periods 7 and 8 we find similar results. As earlier, we performed a regression analysis with all the risk taking variables as the independent variables and the SPI at period 7 as the dependant variable.

We found that for low performers the regression model is not significant at the end of period $7(\mathrm{~F}=2.402, d f=$ $5,9,14, p=0.120 ; R^{2}=0.572$ ) whereas at the end of period 8, after the reward manipulation, the same regression model is found to be significant $\left(\mathrm{F}=2.641, d f=5,9,14, p=0.097 ; R^{2}=0.595\right)$. It gives support to our assumption that low performers took more risks during the periods where there was performance-linked monetary reward and provides evidence to support H2a.

The same model for high performers was again found to be significant in both the periods 7 and 8 . $(\mathrm{F}=2.402, d f=$ $5,9,14, p=0.120$ ).

Additionally, for high performers we also found that none of the risk taking variables increased significantly between periods 7 and 8, an evidence which supports H2b. (Period 7- Advertising expenditure - $M=7392.13, S D=1085.71$, Advertising research expenditure $-M=1272.6, S D=364.85$, Sales force- $M=4103.66, S D=792.33$, Market research studies $-M=588, S D=75.21$, Research and development costs- $M=1575.73, S D=731.39$; Period 8- Advertising expenditure $-M=7409.06, S D=1016.21$, Advertising research expenditure - $\mathrm{M}=1298.8, \mathrm{SD}=360.56$, Sales force $-M=4240.13, \mathrm{SD}=707.99$, Market research studies $-M=563, S D=75.19$, Research and development costs- $M=1679$, $S D=589.44 ; \mathbf{T}$ values and significance levels- Advertising expenditure $-t(28)=-0.044, p=0.965$, Advertising research expenditure $-t(28)=-0.198, p=0.845$, Sales force $-t(28)=-0.497, p=0.623$, Market research studies $-t$ $(28)=0.910, p=0.37$, Research and development costs- $-t(28)=-0.426, p=0.673)$.

Another interesting finding here is that the net contribution, a metric on which teams have good control and a metric which has a high importance in terms of grades, was found to be increased significantly for low performers between periods 7 and 8 whereas that was not the case with high performers. (Low performers- Period 7- Net contribution $M=18196.3333, S D=1085.7$; Period 8- Net contribution $-M=27166.46, S D=16653.72$; $\mathrm{T}$ values and significance levels- $t(28)=-1.872, p=0.072$; High performers- Period 7- Net contribution $-M=111906.93, S D=69496.94$; Period 8- Net contribution - $M=138597.66, S D=54550.79$; $\mathrm{T}$ values and significance levels- $\mathrm{t}(28)=-1.17, p=0.252)$. To conclude, we can argue that there is enough evidence to support H2a but evidence to support H2b only partially; but at the same time, we also provide interesting insight into the behavior of high performing teams in response to the high performance-linked rewards.

5.3 Performance-linked Rewards and Innovation by Firms in a Less Challenging Task versus Highly Challenging Task

In Markstrat, to study the innovation, we can analyze the number of new brands introduced by the teams or the Research \& developments costs incurred by them, as both these variables are intrinsically linked. Since almost all the firms launched new brands, it was difficult to compare the new brand launches to study the differences between the firms in innovation. However, we could compare the R \& D costs to test the hypothesis.

In the Markstrat simulation used by us, firms were not approved any R \& D budget till the end of period 3 and most of the firms had exhausted the funds allocated to them by period 7, hence making it difficult to study the effect of our reward manipulation between period $7 \& 8$. So, the results described have been studied at the end of period 5 after the first reward manipulation.

As earlier, we found that both the low performers and high performers had responded equally to the performance-linked reward and the R \& D expenditure of both these groups was found to be significantly higher from the previous periods.

(Low performers- Period 7- $\mathrm{R} \& \mathrm{D}$ costs- $M=4387.2, S D=2844.9$; Period 8- $\mathrm{R} \& \mathrm{D}$ costs $-M=6493.8, S D=3442.3$; T values and significance levels- $t(28)=-1.827, p=0.078$; High performers- Period $7-\mathrm{R} \& \mathrm{D}$ costs- $M=7260.9$, 
$S D=3251$; Period 8- $\mathrm{R} \& \mathrm{D}$ costs $-M=11686, S D=4314.4$; $\mathbf{T}$ values and significance levels- $t(28)=-3.172, p$ $=0.004)$.

Typically, we found that the high performers had high R \& D budget initially and had good utilization of budget, which helped them launch new products and thereby enhancing the performance in terms of SPI. But our objective here is to see the effect of performance-linked reward manipulation in the R \& D expenditure of the teams.

To elaborate this, we specifically looked at the percentage increase in the R \& D costs between period 4 and 5 for both these groups. We found that the percentage increase in R \& D expenditure between the low performers and the high performers, is not significant (Low performers- Percentage increase in R \& $\mathrm{D}$ costs- $M=71.02, S D=81.06$; High performers- Percentage increase in $\mathrm{R} \& \mathrm{D}$ costs- $M=88.74, S D=99.17$; T values and significance levels- $t$ $(28)=-0.536, p=0.596)$. It means that both these groups equally increased the innovation effort in response to the performance-linked reward despite their overt performance differences in the earlier periods.

To elaborate the differences further, we performed a regression analysis with percentage increase in $\mathrm{R} \& \mathrm{D}$ expenditure of both the groups till period 4 as the independent variable and the SPI at period 4 as the dependant variable and then compared the results with the same regression model at the end of period 5. We found that for low performers, the percentage increase in R \& D expenditure between period 4 and 5 has significant effect on their stock price index (Providing evidence in support of H3a) $\left(F=3.877, d f=1,13,14, p=0.071, R^{2}=0.23\right.$ ). But for the high performers, the same regression analysis was not found to be significant (Providing evidence in support of H3b) $(F$ $=0.567, d f=1,13,14, p=0.465, R^{2}=0.042$ ).

It means that although both the groups responded equally to the performance-linked reward, it was the low performers who increased their innovation efforts to such an extent that it affected their stock price index giving support to our third hypothesis.

This is a surprising finding because the groups differ by more than 1000 points in their SPI and actually it should have been the high performers who should have responded aggressively to get the rewards instead of the low performers.

\section{Discussion}

Many firms follow the model of performance-linked reward for management at all levels. These rewards are not linked only to intellectual tasks but even to tasks requiring physical effort like sports and endurance. Psychologists challenge this practice as they argue that such practice may not be beneficial to individuals. Our study finds some support to this notion. We find evidence to support that the practice of performance-linked reward may benefit the low performers more than the high performers and that the high performers may actually 'not push' themselves hard for the performance-linked rewards and can also deliberately lower the performance levels.

The findings are counterintuitive specifically for the high performers where we find that all performance metrics including risk taking tendencies and innovative efforts for these teams actually dip down in response to the high performance-linked reward, which is contrary to the popular notion and practice. Our results also indicate that the managerial behavior at an optimal level of challenge or reward may benefit the firm but an over motivated approach taken by the management may actually deviate from the optimum and can be detrimental to the firm performance. Our research suggests that high performance linked reward may actually decrease the performance of a firm by shifting the main focus from the performance to the incentives in a mangers' mind.

\section{Managerial Implications}

Providing high incentives to get a better work performance is a conventional practice among the managers. Our research and recent research in psychology cited in this paper, provides support that this relationship may not be linear and positive in all the cases.

Looking beyond social psychology and business administration domains, even in public administration literature there is evidence supporting the ineffective nature of performance-linked rewards. Research on the government data provides evidence that the performance-linked rewards have not worked effectively for the governments but government bodies are still reluctant to abandon it due to their conventional beliefs in it. (Kellough \& Lu, 1993; Bowman, 2010) Research also suggests that although it's not correct that performance-linked reward will not work under any circumstances but the evidence shows that "ideal conditions are rarely met in empirical reality" (Bowman, 2010; Gabris \& Ihrke, 2004, p. 540). Also the evidence suggests that in future, employees may "eventually come to see merit pay as a kind of punishment" (Bowman, 2010; Bohnet \& Eaton, 2003, p. 251). 
Senior management in organizations have to realize that in a highly challenging task and under a performance pressure, the performance-linked reward may not act as a motivation but may add to the pressures and challenges of the managers thereby reducing the performance rather than enhancing it. Our research suggests that managers should be motivated by the performance-linked rewards only up to a threshold up to which the performance metrics improve but beyond that optimum, these rewards can be detrimental to the managerial performance. We recommend that multiple small incentives linked to less challenging tasks will work better for the managers than a very high performance-linked reward with a highly challenging task (Ehrenberg \& Bognanno, 1990; Lazear, 2000).

\section{Limitations}

Notwithstanding the contributions, our study has limitations which present opportunities for future research. Firstly, our study examines the managerial behavior using participants in a business school in a Markstrat simulation (Larréché \& Gatignon, 2003). Although researchers have regularly used Markstrat as a realistic setting for studying decision making behavior (Larréché, 1987) and its external validity is proven due to the realistic simulated environment (Aronson, Wilson \& Akert, 1994). Still our findings can be strengthened by additions of a field study or by doing a similar study in Markstrat on the working mangers. Secondly, in this research we used a performance-linked reward metric which was kept fixed for all the subjects due to constraints of a graded course in a student's population. However the future research can focus on the varying difficulty levels linked to performance-linked rewards. Such an approach can better alienate the optimal point of risk-reward ratio and the acceptable levels of risks and difficulties.

To conclude we quote from two recent studies in this field:

"The reality is that pay for performance is likely to be of little benefit to organizations with serious performance problems and may actually be harmful" (James Perry, 2003, p. 150). "Nonetheless, practices are seldom discarded simply because they are dysfunctional; rather, pay-for-performance programs may well have become an urban legend. Debunking such folk myths is not likely to have much effect because of their very nature: The tales are compelling because they reinforce world views about human behavior and provide common sense explanations of complex phenomena" (Bowman, 2010, $\mathrm{p}$ $81)$.

\section{References}

Ariely, D., Gneezy, U., Loewenstein, G., \& Mazar, N. (2009). Large Stakes and Big Mistakes. Review of Economic Studies, 76(2), 451-469. http://dx.doi.org/10.1111/j.1467-937X.2009.00534.x

Aronson, E., Wilson, T. D., \& Akert, R. M. (1994). Social Psychology : The Heart and the Mind. New York, NY: HarperCollins College Publishers.

Baumeister, R. F. (1984). Choking under pressure: Self-Consciousness and Paradoxical Effects of Incentives on Skillful Performance. Journal of Personality and Social Psychology, XL(VI), 610-620. http://dx.doi.org/10.1037/0022-3514.46.3.610

Baumeister, R. F., \& Carolin, J. S. (1986). A review of paradoxical performance effects: Choking under pressure in sports and mental tests. European Journal of Social Psychology, XVI, 361-383. http://dx.doi.org/10.1002/ejsp.2420160405

Beilock, S. L., \& Carr, T. H. (2001). On the fragility of skilled performance: What governs choking under pressure? Journal of Experimental Psychology: General, 130, 701-725. http://dx.doi.org/10.1037/0096-3445.130.4.701 PMid:11757876

Bohnet, I., \& Eaton, S. (2003). Does performance pay perform? Conditions for success in the public sector. In J. Donahue \& J. Nye, Jr. (Eds.), For the people: Can we fix the public service? (pp. 238-254). Washington, DC: Brookings Institution Press.

Butler, J. L., \& Baumeister, R. F. (1998). The trouble with friendly faces: Skilled performance with a supportive audience. Journal of Personality and Social Psychology, 75, 1213-1230. http://dx.doi.org/10.1037/0022-3514.75.5.1213 PMid:9866184

Camerer, C. F., \& Hogarth, R. (1999). The effects of financial incentives in experiments: A review and capital-labor-production framework. Journal of Risk and Uncertainty, 19(1), 7-42. http://dx.doi.org/10.1023/A:1007850605129 
Camerer, C. F., Loewenstein, G., \& Prelec, D. (2005). Neuroeconomics: How Neuroscience Can Inform Economics. Journal of Economic Literature,43(1), 9-64. http://dx.doi.org/10.1257/0022051053737843

Dandy, J., Brewer, N., \& Tottman, R. (2001). Self-Consciousness and Performance Decrements within a Sporting Context. Journal of Social Psychology, 141(1), 150-152. http://dx.doi.org/10.1080/00224540109600540 PMid:11294159

Easterbrook, J. A. (1959). The Effect of Emotion on Cue Utilization and the Organization of Behavior. Psychological Review, 66(3), 183-201. http://dx.doi.org/10.1037/h0047707

Ehrenberg, R. G., \& Bognanno, M. L. (1990). Do Tournaments Have Incentive Effects?. Journal of Political Economy, 98(6), 1307-1323. http://dx.doi.org/10.1086/261736

Fenigstein, A., \& Carver, C. S. (1978). Self-focusing effects of heartbeat feedback. Journal of Personality and Social Psychology, 36, 1241-1250. http://dx.doi.org/10.1037/0022-3514.36.11.1241 PMid:745034

Gabris, G., \& Ihrke, D. (2004). Merit pay and employee performance. In M. Holzer \& S. Lee (Eds.), Public productivity handbook (pp. 499-514). New York: Dekker.

Gneezy, U., \& Aldo, R. (2000). A fine is a price. Journal of Legal Studies, XX(IX), 1-18. http://dx.doi.org/10.1086/468061

Gneezy, U., \& Aldo, R. (2000, August). Pay enough or don't pay at all. The Quarterly Journal of Economics, CXV, 791-810. http://dx.doi.org/10.1162/003355300554917

James, S. B. (2010). The Success of Failure: The Paradox of Performance Pay. Review of Public Personnel Administration, 30(1), 70-88. http://dx.doi.org/10.1177/0734371X09351824

Kellough, J., \& Lu, H. (1993). The paradox of merit pay. Review of Public Personnel Administration, 13, 5-21.

Kimble, G. A., \& Perlmuter, L. C. (1970). The problem of volition. Psychological Review, 77, 361-384. http://dx.doi.org/10.1037/h0029782

Langer, E. J., \& Lois, G. I. (1979). When practice makes imperfect: the debilitating effects of overlearning. Journal of Personality and Social Psychology, XXXVII, 2014-2024. http://dx.doi.org/10.1037/0022-3514.37.11.2014

Larréché, J. C. (1987). On Simulations in Business Education and Research. Journal of Business Research, 15(6), 559-571. http://dx.doi.org/10.1016/0148-2963(87)90039-7

Larréché, J. C., \& Gatignon, H. (2003). Markstrat Online. Paris: StratX International.

Lazear, E. P. (2000). Performance Pay and Productivity. American Economic Review, 90(5), 1346-1361. http://dx.doi.org/10.1257/aer.90.5.1346

Lewis, B., \& Linder, D. (1997). Thinking about choking? Attentional processes and paradoxical performance. Personality and Social Psychology Bulletin, 23, 937-944. http://dx.doi.org/10.1177/0146167297239003

McGraw, K. O., \& John, C. McCullers. (1979). Evidence of a Detrimental Effect of Extrinsic Incentives on Breaking a Mental Set. Journal of Experimental Social psychology, XV, 285-294. http://dx.doi.org/10.1016/0022-1031(79)90039-8

Perry, J. (2003). Compensation, merit pay, and motivation. In S. Hays \& R. Kearney (Eds.), Public personnel administration: Problems and prospects (pp. 143-153). Englewood Cliffs, NJ: Prentice Hall.

Wegner, D. M., \& Giuliano, T. (1980). Arousal-induced attention to self. Journal of Personality and Social Psychology, 38, 719-726. http://dx.doi.org/10.1037/0022-3514.38.5.719

Wine, J. (1971). Test anxiety and direction of attention. Psychological Bulletin, 76, 92-104. http://dx.doi.org/10.1037/h0031332

Yerkes, R. M., \& John, D. D. (1908). The relationship of strength of stimulus to rapidity of habit-formation. Journal of Comparative Neurology of Psychology, XVIII, 459-482. http://dx.doi.org/10.1002/cne.920180503 